Monográfico: Reflujo Vesicoureteral

Arch. Esp. Urol., 61, 2 (180-184), 2008

\title{
ACTUALIZACIÓN VIDEOURODINÁMICA DE LA CLASIFICACIÓN DEL REFLUJO VESICOURETERAL EN EL NIÑO
}

Jesús Salinas Casado, Carlos Martín García, Miguel Virseda Rodríguez, Juan Carlos Ramírez Fernández y Ángel Silmi Moyano.

Servicio de Urología. Hospital Clínico San Carlos. Universidad Complutense de Madrid. Madrid. España.

Resumen.- OBJETIVO: La actualización de la clasificación del reflujo vesicoureteral en el niño.

MÉTODOS: Videourodinámica.

RESULTADOS: Se tipifican los distintos tipos de reflujo vesicoureteral en el niño.

CONCLUSIONES: Se sigue demostrando la utilidad de dicha clasificación con la introducción de algunas modificaciones, necesarias para su continua actualización.

Palabras clave: Videourodinámica. Reflujo vesicoureteral. Niño.
Summary.- OBJECTIVES: To update the classification of vesicoureteral reflux in children.

METHODS: Videourodynamics.

RESULTS: We categorize the different types of vesicoureteral reflux in children.

CONCLUSIONS: The usefulness of the classification is demonstrated, with the introduction of some modifications necessary for its continuous updating.

Keywords: Videourodynamics. Vesicoureteral reflux. Pediatrics.

\section{INTRODUCCIÓN}

La terminología sobre el reflujo vesicoureteral es muchas veces confusa, hablándose de reflujo primario, secundario, Shopfner (1), Ransley (2), activo y pasivo Colodny (3). Otras clasificaciones atienden a unilateralidad o bilateralidad, así como el grado de reflujo Bridge (4).

Salinas y cols. (5) describieron una nueva clasificación videourodinámica del reflujo vesicoureteral, que fue revisada posteriormente una década después Salinas y cols. (6).

\section{MÉTODO}

\section{VIDEOURODINÁMICA}

La videourodinámica es la exploración urodinámica en la que se asocia simultáneamente, al estudio urodinámico convencional, el registro continuo del tracto urinario inferior (tanto de la fase de llenado como de la miccional). La videourodinámica, por tanto, tiene dos características propias. 
1. Es una técnica cinética: registra los cambios morfológicos del tracto urinario inferior en el tiempo. Este dato le diferencia del registro gráfico estático propio de la cistografía aislada.

2. Es una técnica simultánea al estudio urodinámico convencional.

Para la realización de un estudio videourodinámico se precisan tres requisitos:

1. La obtención de imágenes cinéticas (en movimiento) del tracto urinario inferior.

2. La realización de un estudio urodinámico convencional.

3. La integración de ambos estudios.

\section{1) Obłención de imágenes cinéticas del tracto uri- nario inferior}

El registro gráfico del tracto urinario inferior se realiza actualmente mediante emisión de rayos $X$.

\section{Emisión de rayos $X$}

Para facilitar esta exploración, lo ideal es acostar al niño en una mesa giratoria en los dos ejes del espacio, que permita colocarlo en la situación más apropiada para visualizar el tracto urinario inferior. El principal objetivo es obtener una reproducción fiable del tracto urinario inferior. Por eso se suele colocar al niño en posición de bipedestación, y a la niña en sedestación.

La orientación del paciente respecto al emisor de rayos $X$ también es importante. Generalmente, durante la fase de llenado, el emisor se coloca centrado en el pubis con el plano cefalocaudal del niño paralelo al emisor. Durante la fase miccional, se rota la pelvis del niño de manera que quede situada en posición oblicua respecto al emisor de rayos $X$, con el fin de mejorar la visualización del cuello vesical y de la uretra posterior.

\section{2) Realización de un estudio urodinámico con- vencional}

Este estudio se debe realizar simultáneamente al registro gráfico del tracto urinario inferior. La técnica para su realización es la misma que la de los estudios urodinámicos convencionales. La única diferencia radica en el medio de infusión empleado, que en el caso de la utilización de un emisor de rayos $X$, debe ser un medio de contraste radiológico para poder hacer opacas las estructuras urinarias.

\section{3) Integración del registro gráfico y del estudio urodinámico}

La integración de ambos tipos de estudios requiere de su grabación en un soporte adecuado para su posterior reproducción.

Los primitivos estudios utilizaban equipos de cinerradiografía, grababan conjuntamente ambos tipos de da- tos, en emulsión química (película de cine). Posteriormente, la aparición de los magnetoscopios permitió el registro magnético simultaneo ("video-tapes").

Actualmente, el desarrollo de la tecnología informática ha facilitado la integración de ambos tipos de datos en un mismo soporte, mediante su digitalización. El inconveniente es la gran cantidad de memoria necesaria para su almacenamiento, por lo que se aconseja disponer de una unidad grabadora de compact disc (CD-R o mejor CD-RW) para almacenar los estudios realizados. La aparición de grabadoras DVD ha mejorado significativamente la capacidad para almacenar datos.

Los estudios videourodinámicos valoran tanto la fase de llenado vesical, como miccional. Habrá que tener presente en su realización, la edad del niño, en el sentido de las limitaciones de su colaboración y evitar la sobreirradiación genital. Habrá que considerar que la aportación de síntomas, por parte del niño (frente al adulto), suele ser pobre.

Así pues, los estudios videourodinámicos proporcionan una información integrada de la morfología y la función del tracto urinario inferior. Sus principales limitaciones son el elevado coste económico y la complejidad del estudio, por lo que sus indicaciones deben restringirse a los procesos en que sean verdaderamente necesarios.

En la Tabla I vienen descritas las principales indicaciones de la videourodinámica en el reflujo vesicoureteral del niño, frente a otras técnicas urodinámicas.

\section{RESULTADOS}

Como viene expuesto en la Tabla II, se distinguen dos clases de reflujo vesicoureteral: pasivo y activo. El reflujo pasivo se divide a su vez, según los datos de la cistomanometría, en dos tipos:

1 Reflujo pasivo con acomodación vesical normal: este tipo se caracteriza porque se presenta durante la fase de llenado vesical y no se demuestra hiperactividad o aumento de la contractilidad del detrusor o de la presión intraabdominal durante el mismo, y la acomodación es normal (Figura 1).

2 Reflujo pasivo con baja acomodación: este también se caracteriza por presentarse en la fase de llenado sin contracciones del detrusor, ni aumento de la presión abdominal, pero la acomodación vesical está disminuida (Figura 2).

El reflujo activo según los datos de la cistomanometría y estudio de presión flujo, se divide en:

10 Reflujo activo involuntario: es el producido por una contracción involuntaria del detrusor durante la fase de llenado vesical. Se asocia a hiperactividad del detrusor y puede ser idiopático (Figura 3), o bien secundario, cuando la hiperactividad es secundaria a otro proceso como obstrucción del tracto urinario inferior (Figura 4), hiperreflexia vesical o disfunción miccional. 
TABLA I. INDICACIONES TÉCNICAS URODINÁMICAS EN EL NIÑO. (REFLUJO VESICOURETERAL).

\begin{tabular}{|l|l|l|l|l|}
\hline & Enuresis & Obstrucción TUI & Reflujo vesicoureteral & $\begin{array}{l}\text { Disfunción neurógena } \\
\text { congénita }\end{array}$ \\
\hline Flujometría & $+/-$ & + & $+/-$ & + \\
\hline Flujometría + EMG & ++ & + & + & ++ \\
\hline Cistomanometría & ++ & $+/-$ & ++ & ++ \\
\hline Estudio presión-flujo & + & + & ++ & $+/-$ \\
\hline Videourodinámica & + & ++ & ++ & ++ \\
\hline EMG+ Cistomanom. & ++ & + & + & ++ \\
\hline EMG selectiva & $+/-$ & $+/-$ & $+/-$ & + \\
\hline
\end{tabular}

$+/-:$ Dudosa, + : Interesante; ++:Fundamental.

2 Reflujo vesical activo voluntario: se caracteriza porque el reflujo se asocia con la contracción voluntaria del detrusor durante la micción. Se puede asociar o no a obstrucción del tracto urinario inferior.

3 Reflujo vesicoureteral activo con prensa abdominal (Figura 5): se refiere al que se presenta cuando se producen grandes presiones intravesicales por la transmisión de elevadas presiones intraabdominales utilizadas en la evacuación urinaria, generalmente en casos de detrusor acontráctil.

Posteriormente Salinas y Virseda introducen algunas modificaciones a la clasificación original que vienen recogidas en la Tabla III.

\section{TABLA II. CLASIFICACIÓN DEL REFLUJO VESICOURETERAL.}

\begin{tabular}{|l|l|}
\hline \multirow{2}{*}{ PASIVO } & Acomodación vesical normal \\
\cline { 2 - 2 } & Acomodación vesical disminuida \\
\hline \multirow{2}{*}{ ACTIVO } & $\begin{array}{c}\text { Involuntario } \\
\text { Idiopático } \\
\text { Secundario }\end{array}$ \\
\cline { 2 - 2 } & Voluntario \\
& Por prensa abdominal \\
\hline
\end{tabular}

Se refiere en primer lugar al reflujo pasivo, esto es, al que se presenta en la fase de llenado vesical. En ocasiones, el reflujo pasivo no se presentaría originalmente con dicho carácter (primario), sino que inicialmente sería de carácter activo involuntario, activo voluntario o por prensa abdominal, y posteriormente se convertiría en pasivo, al forzar la unión ureterovesical. Es lo que se conoce como reflujo pasivo evolutivo. No obstante, para confirmar esto, se precisaría de un estudio longitudinal.

La otra modificación de la nueva clasificación se referiría al reflujo activo voluntario.

\section{REFLUJO PASIVO/ACOMODACIÓN NORMAL}

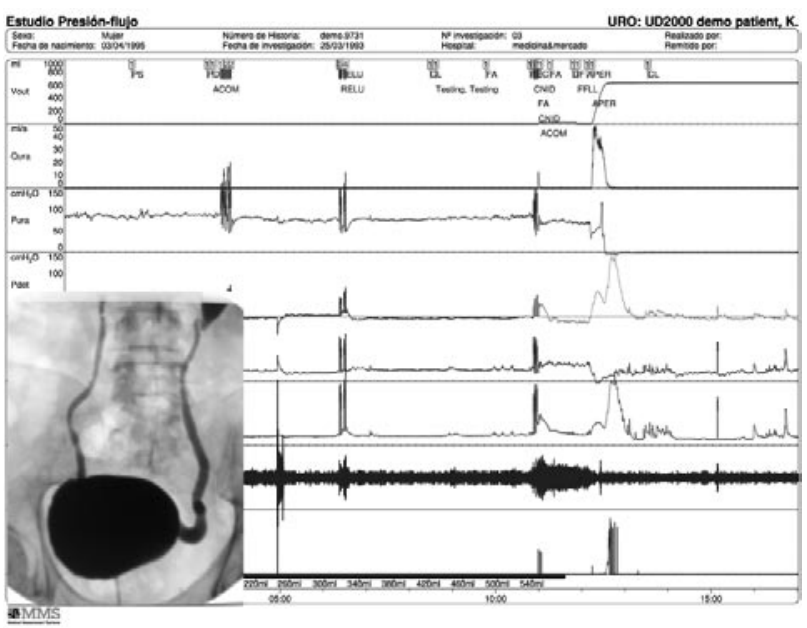

FIGURA 1. Videourodinámica. Reflujo vesicoureteral pasivo bilateral con acomodación vesical normal. De arriba abajo: volumen miccional, flujo miccional, presión uretral, presión detrusor, presión abdominal, presión vesical, EMG perineal y volumen infusión. 


\section{REFLUJO PASIVO/BAJA ACOMODACIÓN}

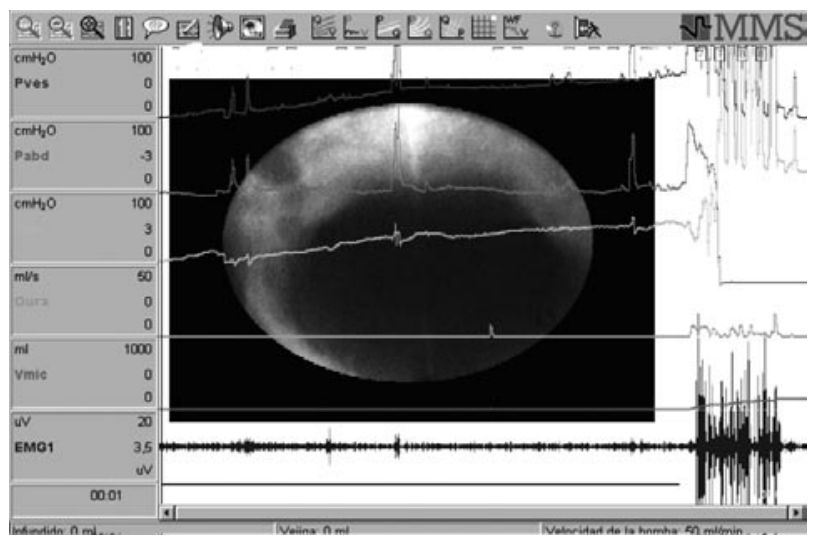

FIGURA 2. Videourodinámica. Reflujo vesicoureteral pasivo derecho. Acomodación vesical disminuida. De arriba abajo: presión vesical, presión abdominal, presión detrusor, flujo miccional, volumen miccional, electromiografía perineal.

Generalmente el reflujo activo voluntario es secundario a una obstrucción del tracto urinario inferior, pero asimismo puede presentarse en ocasiones, sin asociarse a dicha condición, como en casos de vejigas con gran capacidad contráctil del detrusor durante la micción, (no infrecuente en niños), o incluso sin necesidad de grandes presiones del detrusor miccionales. Naturalmente, esto implica cierto defecto en la unión ureterovesical y su corrección exigiría en el primer caso un tratamiento anticolinérgico ly si no responde reimplante ureterovesical), y en el segundo caso un reimplante ureterovesical.

\section{REFLUJO ACTIVO INVOLUNTARIO SECUNDARIO A OBSTRUCCIÓN DE URETRA DISTAL (MUJER)}

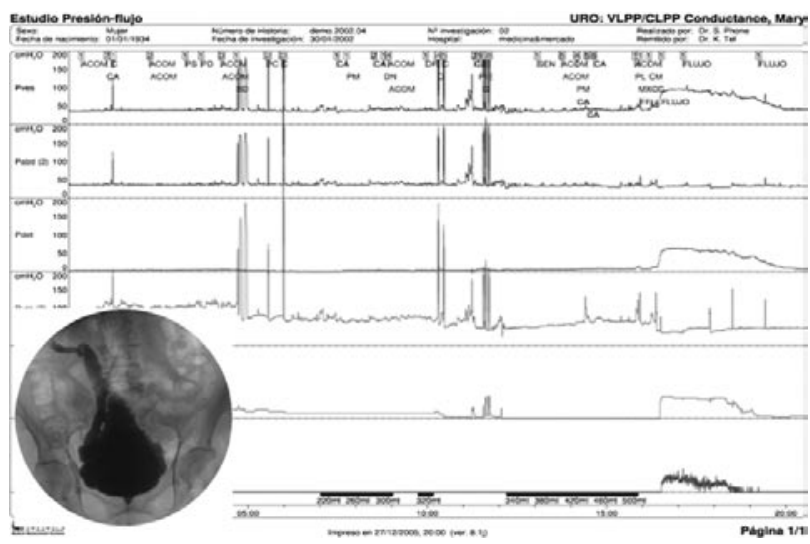

FIGURA 4. Videourodinámica. Reflujo vesicoureteral activo involuntario, lado derecho, secundario a obstrucción uretra distal niña. De arriba abajo: presión vesical, presión abdominal, presión detrusor, presión uretral, presión uretral y flujo miccional.

\section{REFLUJO ACTIVO INVOLUNTARIO IDIOPÁTICO}

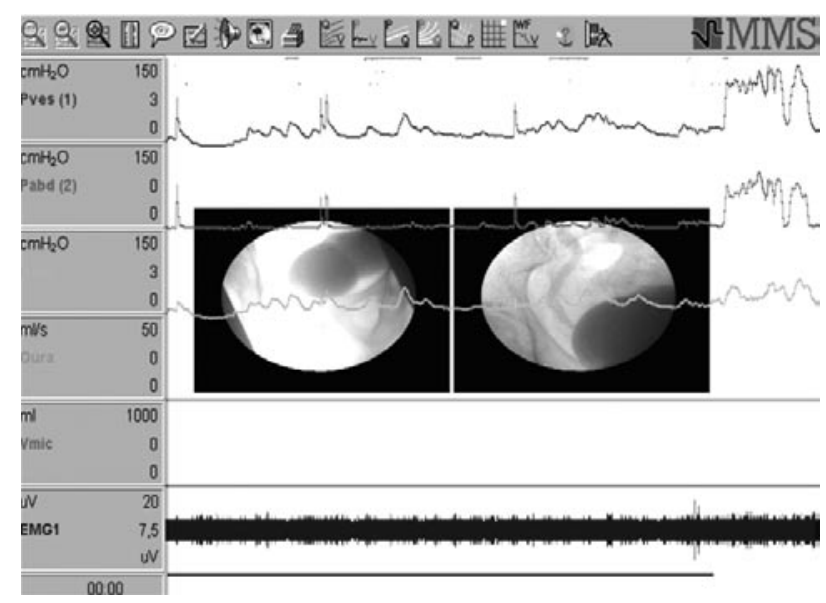

FIGURA 3. Videourodinámica. Reflujo vesicoureteral activo involuntario idiopático, lado derecho. De arriba abajo: presión vesical, presión abdominal, presión detrusor y electromiografía perineal.

\section{DISCUSIÓN}

En una serie de Salinas y cols. (6), el tipo de reflujo vesicoureteral más frecuente fue el activo involuntario secundario a vejiga neurógena.

La clasificación urodinámica del reflujo vesicoureteral aporta conceptos fundamentales desde el punto de vista terapéutico en esta patología, ya que se basa en el mecanismo patofisiológico de producción del propio reflujo. En el reflujo pasivo, es importante destacar la nece-

\section{REFLUJO PRENSA ABDOMINAL}

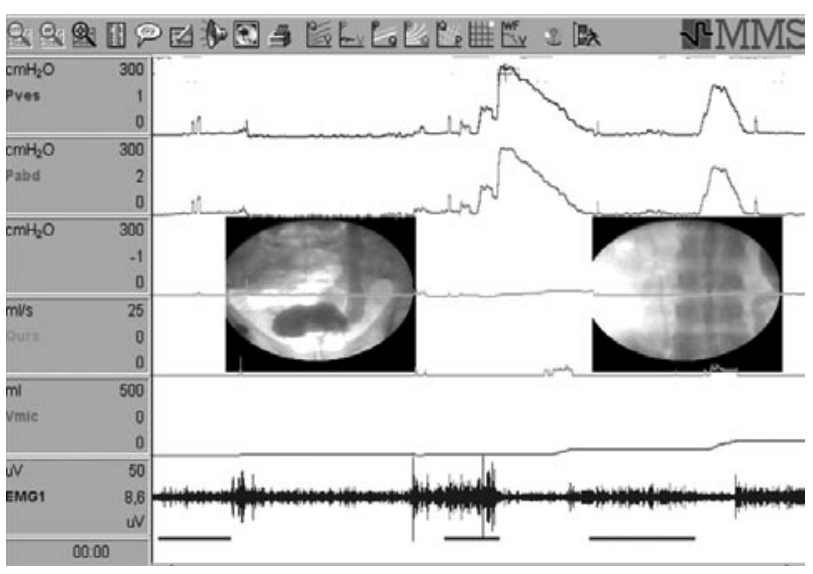

FIGURA 5. Videourodinámica. Reflujo vesicoureteral por presion abdominal, lado izquierdo. De arriba abajo: presión vesical, presión abdominal, presión detrusor, flujo miccional, volumen miccional, electromiografía perineal. 
TABLA III. CLASIFICACION ACTUAL VIDEOURODINAMICA DEL REFLUJO VESICOURETERAL.

\begin{tabular}{|c|c|c|c|}
\hline Tipo de reflujo & $\begin{array}{c}\text { Acomodación vesical } \\
\text { durante el reflujo }\end{array}$ & $\begin{array}{c}\text { Tipo de actividad detrusor } \\
\text { durante el reflujo }\end{array}$ & Evolución \\
\hline Pasivo primario & Normal & Ausente & Ausente \\
\hline Pasivo evolutivo & Normal & Ausente & Presente $^{*}$ \\
\hline Pasivo con baja acomodación & Disminuida & Ausente & Ausente \\
\hline Activo involuntario & Normal & Involuntaria $\dagger$ & Ausente \\
\hline Activo voluntario & Normal & Voluntaria $\ddagger$ & Ausente \\
\hline Prensa abdominal & Normal & Ausente§ & Ausente \\
\hline
\end{tabular}

* La evolución puede ser a partir de un reflujo activo involuntario, activo voluntario o con prensa abdominal.

† La contracción involuntaria puede ser idiopática o secundaria.

‡ Este tipo de reflujo puede asociarse a ausencia de obstrucción del TUI, obstrucción del TUI, ó aumento de la potencia contráctil del detrusor.

$\S$ Este tipo de reflujo se produce durante la evacuación urinaria por prensa abdominal.

sidad del estudio videourodinámico, pues con la simple cistouretrografía se pueden eludir erroneamente contracciones involuntarias del detrusor que sean las responsables del mismo, atribuyéndolo únicamente al fallo de la válvula ureterovesical, cuando en realidad se trataria de un reflujo activo involuntario.El manejo terapeútico sería fundamentalmente distinto.

En otras ocasiones, el reflujo pasivo se acompaña de una acomodación vesical disminuida, generalmente en casos de disfunción vesicouretral tipo neurona motora inferior.

En el reflujo vesicoureteral activo siempre media algún tipo de actividad contráctil del músculo detrusor o de la prensa abdominal.

En la mayoría de los pacientes con reflujo vesicoureteral activo, éste es involuntario, y se produce en la fase de llenado, con lo que un estudio cistouretrográfico aislado nos puede llevar a un diagnóstico erróneo de reflujo pasivo por defecto de la unión ureterovesical.

El reflujo activo involuntario (reflujo asociado a hiperactividad del detrusor) se puede presentar en la fase de llenado vesical, o precipitar la fase miccional, esto es puede presentarse en ambas fases. Por el contrario, el reflujo activo voluntario se presenta sólo en la fase micional.

Hay que huir de un concepto muy extendido, que caracteriza un reflujo de pasivo, cuando se demuestra durante la fase de llenado vesical, y reflujo activo cuando se demuestra durante la fase miccional.

Después de la descripción de la original clasificación, Salinas y Virseda (7) mantienen la utilidad de la clasificación videourodinámica del reflujo vesicoureteral, incluyendo las modificaciones correspondientes al reflujo pasivo evolutivo (frente al primario) y reflujo activo voluntario, en orden a una tipificación más completa.

\section{BIBLIOGRAFÍA Y LECTURAS RECOMENDADAS ( 'lectura de interés $y$ ** lectura fundamental)}

1. SHOPNER, C.E.: "Vesicoureteral reflux". Radiology, 95: 637, 1979.

2. RANSLEY, P.G.: "Vesicoureteric reflux". Pediatric. Urology, 15: 152. Ed. by Williams D.I. and Johnston J.H. Butterworths, 1982.

3. COLODNY, A.H.; LEBOWITZ, R.L.: "The importance of voiding during a cystourethrogram". J. Urol., 111: 838, 1974.

4. BRIDGE, R.A.C.; ROE, C.W.: "The grading of vesicoureteral reflux: A guide to therapy". J. Urol., 101: 831, 1969.

*5. SALINAS, J.; PRIETO, L.; PAEZ, A. y cols.: "Nueva clasificación del reflujo vesicoureteral". Arch. Esp. Urol., 45: 449, 1992.

*6. SALINAS, J.; MARTIN, C.; VIRSEDA, M. y cols.: "Comprobación de la utilidad clinica de la clasificación urodinámica del reflujo vesicoureteral en el niño". Urod. A., 15: 7, 2002.

**7. SALINAS, J.; VIRSEDA, M.: "Urodinámica pediátrica". En controversias en urodinámica. $\mathrm{P}$ 369-380. Ed Salinas J., Virseda M. Pub Entheos. Madrid. 2006. 